\title{
$\begin{array}{ll}\text { Research Square } & \text { Preprints are preliminary reports that have not undergone peer review. } \\ \text { They should not be considered conclusive, used to inform clinical practice, } \\ \text { or referenced by the media as validated information. }\end{array}$
}

\section{Influence of interleukin-18 polymorphisms on kidney transplantation outcomes: a meta-analysis}

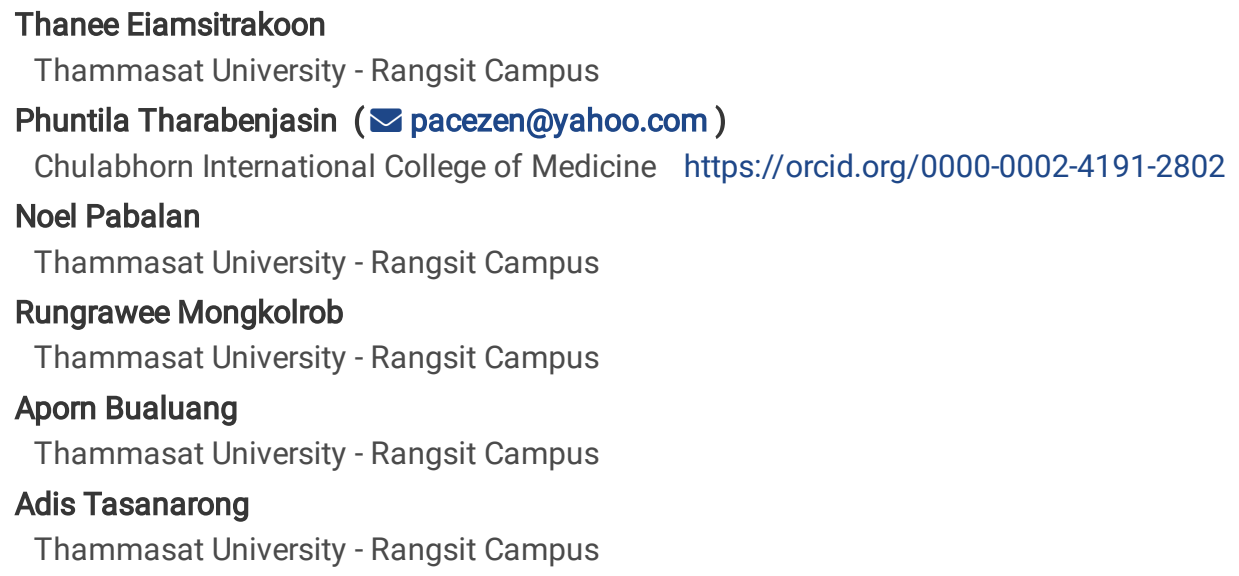

Research article

Keywords: IL-18 polymorphisms, allograft, kidney transplantation, renal, meta-analysis

Posted Date: December 23rd, 2019

DOl: https://doi.org/10.21203/rs.2.19514/v1

License: (9) (1) This work is licensed under a Creative Commons Attribution 4.0 International License. Read Full License 


\section{Abstract}

Objective: Kidney transplantation (KT) procedures are confronted with adverse outcomes that include allograft failure. Allograft survival are in large part attributed to genetics, which render the recipient susceptible or protected from allograft rejection. The genetics of KT outcomes point to single nucleotide polymorphisms (SNPs) where studies have reported the role of cytokines in allograft survival, one of which is interleukin-18 (IL-18). Reported associations of IL-18 with KT outcomes have been inconsistent. This prompted a meta-analysis to obtain more precise estimates.

Methods: From four included articles, we posed two hypotheses about IL-18SNPs: (1) they are either high in patients (hp) /controls (hc) based on genotype distribution (GD) and (2) they either increase or decrease the risks of allograft rejection. To this end, we compared the IL18 genotypes to estimate odds ratios [ORs] and $95 \%$ confidence intervals using standard genetic models (homozygous, recessive, dominant and codominant). Subgrouping was ethnicity-based. Heterogeneous (random-effects) associations were subjected to outlier treatment which split the outcomes as pre- (PRO) and post- (PSO) outlier. Stability and robustness of the outcomes were analyzed by Bonferronicorrection and sensitivity treatment, respectively.

Results: Our results revealed two core outcomes based on significance $\left(\mathrm{P}^{\mathrm{a}}<0.05\right)$ : $(1)$ genotype frequency was hp than hc $\left(\mathrm{OR} 1.34, \mathrm{P}^{\mathrm{a}}=\right.$ $0.0007)$ in the codominant model (PSO) based on stability and robustness and (2) protection from allograft rejection $\left(\mathrm{OR} 0.74, \mathrm{P}^{\mathrm{a}}=0.04\right)$ in the dominant model (PRO) based on homogeneity. Subgroup analysis showed that Caucasian and Asian outcomes validated the GD and allograft outcomes, respectively.

Conclusions: The IL-18 SNPs showed associations (hp) with KT up to 1.3-fold and protected KT recipients from allograft rejection (26\%). Subgroup outcomes delineated the Asian and Caucasian effects. Enabled by outlier treatment, these findings were supported by nonheterogeneity. More studies should confirm or counter our findings.

\section{Background}

The end-stage of renal failure resulting from kidney disease [1] points to kidney transplantation (KT) as the optimal therapeutic choice [1, 2]. The transplanted material (allograft) in the recipient is successful only if it is not rejected [3]. Unrejected allografts are expected to perform the functions as normal kidneys. Normal post-KT graft outcomes depend on immunology where variation in immune responses of the recipient is genetically influenced [4]. This variation may help individualize immunosuppressive regimens by identifying alleles that could increase risk or confer protection for immune-mediated complications [5]. Cytokine proteins modulate and mediate the immune response [6] and the gene that encode these proteins influence transcription, yielding differences in cytokine production [7]. Of the cytokine-related factors, interleukin-18 (IL-18) has been identified as a post-KT biomarker [8]. Single nucleotide polymorphisms (SNPs) have been reported to be associated with KT outcomes $[9,10]$. Studies on the role of IL-18 SNPs and KT outcome have helped us to better understand the immunology of renal disease, providing greater insight into the biology of transplantation. However, the primary studies that have examined the role of IL-18 SNPs with KT have varied in their degree of concurrence. Performing a meta-analysis serves to address this variation and may yield clearer estimates of the role of IL-18 SNPs in renal allograft survival post-KT. In this meta-analysis, we examine the genotype distribution behavior between patients and healthy controls in order to establish an association between the polymorphisms and KT outcomes. Operating on the hypothesis that IL-18 SNPs reduce or increase the risk for allograft rejection, we compare rejector (RJ) with nonrejector (NRJ) patients which might provide useful information for transplant genetics.

\section{Methods}

\section{Selection of studies}

Three databases (PubMed, Google Scholar and Science Direct) were searched for genetic association articles as of September 24, 2019. Search terms included: "interleukin", "IL-18", "cytokine", "polymorphisms", "allograft" and "renal transplantation". Where duplicate articles were encountered, the later dated one was selected. Inclusion criteria were (1) studies that associated IL-18SNPs with KT outcomes; (2) IL18 genotype frequencies that compare KT patients and healthy controls, NR and NRJ. (3) genotype frequency data that allowed calculation of the odds ratios (ORs) and $95 \%$ confidence intervals (Cls). Exclusion criteria were studies that (1) did not examine renal allografts or KT outcomes; (2) were reviews; (3) were not about the IL-18 SNPs and (4) had unusable genotype or allele frequencies.

\section{Linkage disequilibrium and data extraction}

The included articles examined two IL-18 SNPs, -137G/C (rs187238) and -607A/C (rs1946518), each presented with genotype data (Table 1 and S1 Table). Observed phenotypic associations have been attributed to the proximity of two SNPs [11, 12]. NCI LDLINK 
(https://ldlink.nci.nih.gov/) results shows that the two SNPS are in linkage equilibrium (LD) based on both European (CEU) and Han (CHB) genotypes [13]. LD is defined as the correlation between alleles located near each other [14] which is measured in terms of D' with a value of 1 indicating complete LD [15]. Therefore, IL-18 SNPs with D' values of 1.00 in this study were reported to be in LD (S1 Table) and combined in the analysis (S2/S3 Table). Given these conditions, rs187238 and rs1946518 SNPs in IL-18 were combined. This combination allowed analysis by GD and allograft as well as subgrouping by ethnicity (Tables 2 and 3).

Two investigators (TE and NP) independently extracted data and arrived at a consensus. The following information was obtained from each publication: first author's name, year of the study, country of origin, ethnicity, age of the subjects, IL-18 SNPs (rs number) and the ClarkBaudouin (CB) score (Table 1). Sample sizes as well as genotype data between the RJ and NRJ were also extracted along with calculated outcome of the minor allele frequency (maf) (S2 and S3 Tables).

\section{Power calculations and HWE assessment}

Using the G*Power program [16], we evaluated statistical power as its adequacy bolsters the level of associative evidence. Assuming an OR of 1.5 at a genotypic risk level of $a=0.05$ (two-sided), power was considered adequate at $\geq 80 \%$. The Hardy-Weinberg Equilibrium (HWE) was assessed using the application in https://ihg.gsf.de/cgi-bin/hw/hwa1.pl.

\section{Methodological quality of the studies}

We used the CB scale to evaluate methodological quality of the included studies [17]. The CB criteria include P-values, statistical power, correction for multiplicity, comparative sample sizes between cases and controls, genotyping methods and the HWE. In this scale, low, moderate and high have scores of $<5,5-6$ and $^{3} 7$, respectively.

\section{Meta-analysis}

We estimated odds ratios (ORs) and $95 \%$ confidence intervals (Cls) of association using two overall approaches: (i) genotype distribution (GD) between cases and healthy controls and (ii) allograft wherein RJ were compared with NRJ. Calculated pooled ORs for GD were either higher in patients (hp) or higher in controls (hc); in allograft, they were either increased (in) or decreased (de), indicating risk for rejection. Standard genetic modeling was used, wherein we compared the following, (i) variant (var) genotype compared with the wild-type (wt) genotype (homozygous: Ho). To address importance of the heterozygous genotype, we evaluated recessive (Rc: wt-wt versus wt-var+ varvar), dominant (Do: wt-wt + wt-varversus var-var) and codominant (Co: wt versus var) effects. Heterogeneity between studies was estimated with the $\mathrm{c}^{2}$-based $\mathrm{Q}$ test [18], with threshold of significance set at $\mathrm{P}^{\mathrm{b}}<0.10$. Heterogeneity was also quantified with the $\mathrm{I}^{2}$ statistic which measures variability between studies [19]. $\left.\right|^{2}$ values of $>50 \%$ indicate more variability than those $£ 50 \%$ with $0 \%$ indicating zero heterogeneity. Evidence of functional similarities in population features of the studies warranted using the fixed-effects model [20], otherwise the random-effects model [21] was used. Sources of heterogeneity were detected with the Galbraith plot [22] followed by re-analysis (outlier treatment). Of note, outlier treatment dichotomized the comparisons into pre-outlier (PRO) and post-outlier (PSO). Sensitivity analysis, which involves omitting one study at a time and recalculating the pooled OR, was used to test for robustness of the summary effects. The low number of studies precluded assessment of publication bias. Data were analyzed using Review Manager 5.3 (Cochrane Collaboration, Oxford, England), SIGMASTAT 2.03 (Systat Software, San Jose, CA, USA) and SPSS 20.0 (IBM Co., Armonk, NY, USA).

\section{Results}

\section{Search outcomes and study features}

Figure 1 outlines the study selection process in a PRISMA-sanctioned flowchart (Preferred Reporting Items for Systematic Reviews and MetaAnalyses). Initial search resulted in 39 citations, followed by a series of omissions that eventually yielded four articles for inclusion [23-26].

\section{Characteristics of the included studies}

Three [24-26] of the four included articles examined the two IL-18 polymorphisms (rs187238 and rs1946518). S2 and S3 Tables show seven studies each for GD and allograft analyses. Under these two analyses, the following studies comprised the two ethnicities: (1) GD: Asian and Caucasian: three and four studies from two $[23,24]$ and two articles $[25,26]$, respectively; $(2)$ allograft: Asian and Caucasian, five from two articles and two studies[23, 24] from one article [25] respectively (Tables 2 and 3). Table 1 shows that the methodological quality of the component studies was moderate based on mean and SD $(6.37 \pm 1.24)$ of the normally distributed CB scores (SW test: $P=0.33)$. This metaanalysis followed the PRISMA guidelines (S5 Table).

\section{Meta-analysis outcomes}


Table 2 delineates the overall pooled ORs by direction of effect, where GDs were hp (OR > 1.00) and decreased risk in the allograft analysis $(O R<1.00)$. The results show five statistically significant ORs $\left(P^{a}<0.05\right)$, three (all PSO) and two outcomes in GD and allograft, respectively. Of the five significant overall pooled ORs, only one survived the Bonferroni correction. This Bonferroni-surviving pooled OR became our core finding in GD, the PSO-derived Co model outcome indicating hp (OR 1.34, 95\% Cl 1.13-1.58, $\left.\mathrm{P}^{\mathrm{a}}=0.0007\right)$. This finding was validated in Caucasian subgroup (OR 1.32, 95\% Cl 1.04 to 1.66, $\left.\mathrm{P}^{\mathrm{a}}=0.02\right)$. Based on homogeneity $\left(\mathrm{I}^{2}=0 \%\right)$ and initial fixed-effects features, the other core outcome was found in the Do model of the allograft analysis (OR 0.74, 95\% $\left.\mathrm{Cl} 0.55-0.98, \mathrm{P}^{\mathrm{a}}=0.04\right)$. This finding was validated in the Asian subgroup (OR $\left.0.70,95 \% \mathrm{Cl} 0.50-0.98, \mathrm{P}^{\mathrm{a}}=0.04\right)$. The mechanism of outlier treatment for $I L-18$ in the Co model of allograft analysis is visualized in Figs 2-4. Fig 2 shows the PRO forest plot with a non-significant $\left(P^{a}=0.48\right)$ and heterogeneous $\left(P^{b}=0.02, I^{2}=60 \%\right)$ pooled effect indicating reduced risk (OR 0.89, 95\% Cl 0.63-1.25). The Galbraith plot identified the two studies [24, 25] as the sources of heterogeneity (outliers), located above the +2 confidence limit (Fig 3). In Fig 4, the PSO outcome (outliers omitted) shows reduced heterogeneity $\left(P^{b}=0.16, I^{2}=39 \%\right)$; reduced risk effect (OR $\left.0.73,95 \% \mathrm{Cl} 0.56-0.93\right)$ and gained significance $\left(P^{a}=0.01\right)$. This operation is numerically summarized in Table 2 . Table 3 shows the outcomes from sensitivity analysis where two of the nine (22\%) comparisons were robust, one of which was the core finding (GD overall PSO).

\section{Discussion}

\section{Summary of associations}

The main findings of this study point to a dichotomized pattern of significant effects where all GD ORs favored patients (hp) over that of controls (up to 1.6-fold). In contrast, all outcomes in the allograft analysis indicated reduced risks of rejection (as much as $30 \%$ ). Subgroup validation of these effects indicate consistency. Bonferroni correction and sensitivity analysis indicate stability and robustness, respectively, of the core outcomes.

In this meta-analysis, subgroup and outlier treatments have unraveled significant and non-heterogeneous and homogeneous associations that were not present in the component single-study outcomes. Conflicting outcomes between primary studies may be attributed to their lack of power and small sample sizes. Underpowered outcomes appear to be common in candidate gene studies [27] and are prone to the risk of Type 1 error.

\section{IL-18 SNPs in allografts}

The crucial role of IL-18 in kidney physiology lies in its involvement in the filtration, integrity and permeability of the glomerular basement membrane [28]. IL-18 expression in renal epithelium might be important in triggering specific immune response manifested as acute graft rejection [29]. Post-KT hypoxia stimulates IL-18 production from the immune cells (neutrophils and macrophages) which permeate the allograft [30]. Moreover, rising levels of IL-18 enable the endothelial cells to ease entry of leukocytes into the allograft which sets the stage for rejection [24]. A study demonstrated an upregulation of IL-18 production in patients with acute rejection of kidney allograft [29]. Moreover, another study found significantly higher levels of IL-18 in culture biopsies from patients with acute rejection in comparison to stable KT patients [31]. Urinary IL-18 has been found to be an early, noninvasive, and accurate predictor for dialysis within the first week of KT [32, 33].

\section{Strengths and limitations}

Interpreting our findings should consider its limitations and strengths. Limitations include: (i) All the component studies were underpowered and (ii) most significant outcomes were non-robust. On the other hand, the strengths comprise of the following: (i) the combined sample sizes translated to adequate statistical power (80\%); (ii) none of the articles had control frequencies that deviated from HWE. Confining the analysis to studies in HWE did not materially alter the pooled ORs; in fact, HWE-analysis validated the overall pooled effects. Given this outcome, the risk of genotyping errors appears to be a minor issue which minimizes methodological weakness in our study. Outlier treatment was key to generating significance and reducing heterogeneity. This demonstrates the utility of this meta-analysis tool in elevating the level of evidence for associations.

\section{Conclusions}

We have shown that associations of the IL-18 SNPs with KT outcomes were genetic model dependent, with significance confined to the $\mathrm{Do} / \mathrm{Co}$ models in the allograft analysis. Consistency of the GD outcomes due to outlier treatment and subgroup analysis pointed to the Do/Co models. The evidence presented here may render $I L-18$ useful as prognostic markers in allograft failure post-KT. In spite of the evidence for associations, the complexity of allograft rejection involves interactions between genetic and non-genetic factors allowing for the possibility of environmental involvement. Interactions of the IL-18 gene with other genes and environmental factors have been reported 
in post-KT allograft rejection. One article [24] examined another gene polymorphism (vascular endothelial growth factor (VEGF)). All articles acknowledged gene-environment interaction. Addressing gene-gene and gene-environment interactions may help address the pathophysiological significance of $I L-18$ in allograft failure post-KT. All articles mentioned haplotype analysis with one presenting haplotype data [24]. Focus on IL-18 haplotypes have been suggested for future association studies [10]. Future studies that focus on aspects other than those covered in this study would facilitate better understanding of $I L-18$ associations with KT outcomes.

\section{Declarations}

-Ethics approval and consent to participate Not applicable

-Consent for publication Not applicable

-Availability of data and material In Supporting information

-Competing interests The authors declare that they have no competing interests

-Funding This study was unfunded

\section{-Authors' contributions}

Conceptualization: TE, PT

Formal analysis: PT, NP

Investigation: TE, PT, NP

Methodology: PT, NP, RM, AB

Resources: PT, AT

Supervision: AT

Validation: TE, PT, NP, RM, AB, AT

Writing - original draft: TE, PT, NP

Writing - review \& editing: TE, PT, NP, RM, AB, AT

All authors have read and approved the manuscript

-Acknowledgements Not applicable

\section{Supporting information}

S1 Table LD matrix DOCX

S2 Table Quantitative features GD DOCX

S3 Table Quantitative features Allograft DOCX

S4 Table HWE analysis DOCX

S5 Table PRISMA checklist DOCX

\section{Abbreviations}

é robust; all other significant outcomes were non-robust

û significant outcomes that did not survive the Bonferroni correction

P significant outcome that survived the Bonferroni correction 
A adenine

AM analysis model

C cytosine

CB Clark-Baudouin

CC homozygous genotype

CEU genomic datasets representing individuals of European ancestry

CHB genomic datasets representing individuals of Han Chinese ancestry

$\mathrm{Cl}$ confidence interval

Co codominant genetic model

de decreased risk

Do dominant genetic model

du duplicate

EH eliminated heterogeneity

Fe fixed-effects

G guanine

GD genotype distribution

GS gained significance

hc higher in controls

het heterogeneity

Ho homozygous genetic model

hp higher in patients

HWE Hardy-Weinberg Equilibrium

$\mathrm{I}^{2}$ measure of variability

IL-18 interleukin-18 gene

IL-18 interleukin-18 protein

in increased risk

KT kidney transplantation

LD linkage disequilibrium

Log OR logarithm of standardized odds ratio

m controls matched with cases

maf minor allele frequency

n number of studies 
NRJ non-rejector

OR odds ratio

$\mathrm{P}^{\mathrm{a}} \mathrm{P}$-value for association

$\mathrm{P}^{\mathrm{b}} \mathrm{P}$-value for heterogeneity

PRO pre-outlier

PSO post outlier

[R] Reference

Rc recessive genetic model

Re random-effects

$\mathrm{RH}$ reduced heterogeneity

RJ rejector

RNS retained non-significance

SD standard deviation

SE standard error

Sig significant

SNP single nucleotide polymorphism

varvariant

wt wild-type homozygotes

$w t$-varheterozygote

\section{References}

1. Levey AS, Atkins R, Coresh J, Cohen EP, Collins AJ, Eckardt KU, Nahas ME, Jaber BL, Jadoul M, Levin A et al: Chronic kidney disease as a global public health problem: approaches and initiatives - a position statement from Kidney Disease Improving Global Outcomes. Kidney international 2007, 72(3):247-259.

2. Howard K, Salkeld G, White S, McDonald S, Chadban S, Craig JC, Cass A: The cost-effectiveness of increasing kidney transplantation and home-based dialysis. Nephrology 2009, 14(1):123-132.

3. Critchley WR, Fildes JE: Graft rejection - endogenous or allogeneic? Immunology 2012, 136(2):123-132.

4. Pawlus J, Sierocka A, Tejchman K, Zietek Z, Romanowski M, Pawlik A, Sienko J, Zukowski M, Ciechanowski K, Ostrowski M et al: The impact of interleukin 12B (1188A>C), interleukin $16(-295 \mathrm{~T}>\mathrm{C})$, and interleukin 18 (607C>A, 137G>C) gene polymorphisms on long-term renal transplant function and recipient outcomes. Transplantation proceedings 2014, 46(6):2079-2082.

5. Kruger B, Schroppel B, Murphy BT: Genetic polymorphisms and the fate of the transplanted organ. Transplantation reviews 2008, 22(2):131-140.

6. Seeger H, Lindenmeyer MT, Cohen CD, Jaeckel C, Nelson PJ, Chen J, Edenhofer I, Kozakowski N, Regele H, Boehmig G et al: Lymphotoxin expression in human and murine renal allografts. PloS one 2018, 13(1):e0189396.

7. Wilson AG, Symons JA, McDowell TL, McDevitt HO, Duff GW: Effects of a polymorphism in the human tumor necrosis factor alpha promoter on transcriptional activation. Proceedings of the National Academy of Sciences of the United States of America 1997, 94(7):3195-3199.

8. Herath S, Erlich J, Au AYM, Endre ZH: Advances in Detection of Kidney Transplant Injury. Molecular diagnosis \& therapy 2019, 23(3):333351. 
9. Israni A, Leduc R, Holmes J, Jacobson PA, Lamba V, Guan W, Schladt D, Chen J, Matas AJ, Oetting WS et al: Single-nucleotide polymorphisms, acute rejection, and severity of tubulitis in kidney transplantation, accounting for center-to-center variation. Transplantation 2010, 90(12):1401-1408.

10. Phelan PJ, Conlon PJ, Sparks MA: Genetic determinants of renal transplant outcome: where do we stand? Journal of nephrology 2014, 27(3):247-256.

11. Liu Y, Lin N, Huang L, Xu Q, Pang G: Genetic polymorphisms of the interleukin-18 gene and risk of prostate cancer. DNA and cell biology 2007, 26(8):613-618.

12. Wei YS, Lan Y, Liu YG, Tang H, Tang RG, Wang JC: Interleukin-18 gene promoter polymorphisms and the risk of esophageal squamous cell carcinoma. Acta oncologica 2007, 46(8):1090-1096.

13. Li YR, van Setten J, Verma SS, Lu Y, Holmes MV, Gao H, Lek M, Nair N, Chandrupatla H, Chang B et al: Concept and design of a genomewide association genotyping array tailored for transplantation-specific studies. Genome medicine 2015, 7:90.

14. Borecki I: Linkage and Association Studies. In: Encyclopedia of Life Sciences. edn.: John Wiley \& Sons, Ltd; 2001.

15. Lewontin RC: On measures of gametic disequilibrium. Genetics 1988, 120(3):849-852.

16. Faul F, Erdfelder E, Lang AG, Buchner A: G*Power 3: a flexible statistical power analysis program for the social, behavioral, and biomedical sciences. Behavior research methods 2007, 39(2):175-191.

17. Clark MF, Baudouin SV: A systematic review of the quality of genetic association studies in human sepsis. Intensive Care Med 2006, 32(11):1706-1712.

18. Higgins JP, Thompson SG, Deeks JJ, Altman DG: Measuring inconsistency in meta-analyses. Bmj 2003, 327(7414):557-560.

19. Higgins JP, Thompson SG: Quantifying heterogeneity in a meta-analysis. Stat Med 2002, 21(11):1539-1558.

20. Mantel N, Haenszel W: Statistical aspects of the analysis of data from retrospective studies of disease. J Nat/ Cancer Inst 1959 , 22(4):719-748.

21. DerSimonian R, Laird N: Meta-analysis in clinical trials. Control Clin Trials 1986, 7(3):177-188.

22. Galbraith RF: A note on graphical presentation of estimated odds ratios from several clinical trials. Stat Med 1988, 7(8):889-894.

23. Kim CD, Ryu HM, Choi JY, Choi HJ, Choi HJ, Cho JH, Park SH, Won DI, Kim YL: Association of G-137C IL-18 promoter polymorphism with acute allograft rejection in renal transplant recipients. Transplantation 2008, 86(11):1610-1614.

24. Mittal RD, Srivastava P, Singh V, Jaiswal P, Kapoor R: Association of common variants of vascular endothelial growth factor and interleukin-18 genes with allograft survival in renal transplant recipients of North India. DNA and cell biology 2011, 30(5):309-315.

25. Kolesar L, Novota P, Krasna E, Slavcev A, Viklicky O, Honsova E, Striz I: Polymorphism of interleukin-18 promoter influences the onset of kidney graft function after transplantation. Tissue antigens 2007, 70(5):363-368.

26. do Nascimento WG, Ciliao DA, Genre J, Gondim DD, Alves RG, Hassan ND, Lima FP, Pereira MG, Donadi EA, de Oliveira Crispim JC: Genetic polymorphisms of Interleukin-18 are not associated with allograft function in kidney transplant recipients. Genetics and molecular biology 2014, 37(2):343-349.

27. Dumas-Mallet E, Button KS, Boraud T, Gonon F, Munafo MR: Low statistical power in biomedical science: a review of three human research domains. Royal Society open science 2017, 4(2):160254.

28. Chen Y, Dawes PT, Packham JC, Mattey DL: Interaction between smoking and polymorphism in the promoter region of the VEGFA gene is associated with ischemic heart disease and myocardial infarction in rheumatoid arthritis. The Journal of rheumatology 2011 , 38(5):802-809.

29. Striz I, Krasna E, Honsova E, Lacha J, Petrickova K, Jaresova M, Lodererova A, Bohmova R, Valhova S, Slavcev A et al: Interleukin 18 (IL18) upregulation in acute rejection of kidney allograft. Immunology letters 2005, 99(1):30-35.

30. Wu H, Craft ML, Wang P, Wyburn KR, Chen G, Ma J, Hambly B, Chadban SJ: IL-18 contributes to renal damage after ischemiareperfusion. Journal of the American Society of Nephrology : JASN2008, 19(12):2331-2341.

31. de Oliveira JG, Xavier PD, Sampaio SM, Tavares IS, Mendes AA: The synthesis by fine-needle aspiration biopsy cultures of IL-7, IL-16 and IL-18 is significantly associated with acute rejection in kidney transplants. Nephron 2002, 92(3):622-628.

32. Hall IE, Yarlagadda SG, Coca SG, Wang Z, Doshi M, Devarajan P, Han WK, Marcus RJ, Parikh CR: IL-18 and urinary NGAL predict dialysis and graft recovery after kidney transplantation. Journal of the American Society of Nephrology : JASN 2010, 21(1):189-197.

33. Parikh CR, Jani A, Mishra J, Ma Q, Kelly C, Barasch J, Edelstein CL, Devarajan P: Urine NGAL and IL-18 are predictive biomarkers for delayed graft function following kidney transplantation. American journal of transplantation : official journal of the American Society of Transplantation and the American Society of Transplant Surgeons 2006, 6(7):1639-1645 


\section{Tables}

Table 1 Characteristics of the included studies in $I L-18$

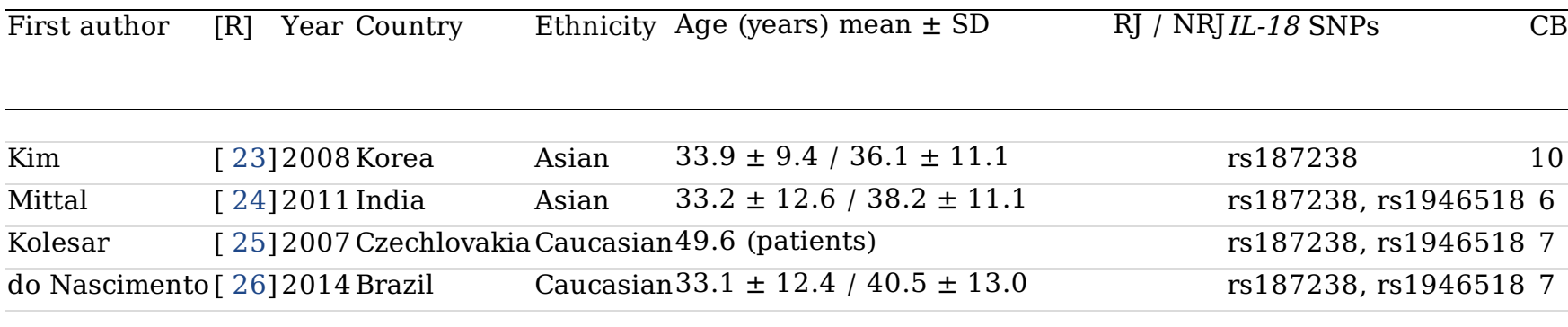

[R] Reference; IL-18: interleukin-18; SD: standard deviation; RJ: rejector; NRJ: non-rejector; SNP: single nucleotide polymorphism; CB: Clark-Baudouin

Table 2 Summary outcomes for $I L-18$

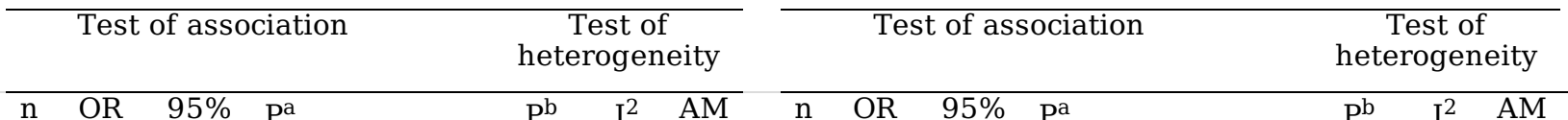

\begin{tabular}{|c|c|c|c|c|c|c|c|c|c|c|c|c|c|c|c|c|c|c|}
\hline & $\mathrm{n}$ & OR & $\begin{array}{c}95 \% \\
\text { CI }\end{array}$ & $\mathrm{P}^{\mathrm{a}}$ & & $\mathrm{P}^{\mathrm{b}}$ & $\begin{array}{c}\mathrm{I}^{2} \\
(\%)\end{array}$ & $\overline{\mathrm{AM}}$ & $\mathrm{n}$ & OR & $\begin{array}{c}95 \% \\
\text { CI }\end{array}$ & $\mathrm{P}^{\mathrm{a}}$ & & $\mathrm{P}^{\mathrm{b}}$ & $\begin{array}{c}\mathrm{I}^{2} \\
(\%)\end{array}$ & AM & $\begin{array}{r}\text { Eff } \\
\text { ou } \\
\text { trea }\end{array}$ & $\begin{array}{l}\text { ct of } \\
\text { lier } \\
\text { ment }\end{array}$ \\
\hline & \multicolumn{8}{|c|}{ PRO } & \multicolumn{8}{|c|}{ PSO } & Sig & Het \\
\hline GD & & & & & Status & & & & & & & & Status & & & & & \\
\hline Ho & 7 & 1.39 & $\begin{array}{l}0.87- \\
2.22\end{array}$ & 0.17 & $\mathrm{hp}$ & 0.07 & 49 & $\mathrm{Re}$ & 5 & 1.63 & $\begin{array}{l}1.16- \\
2.30\end{array}$ & $0.005 \hat{\mathrm{u}}$ & $\mathrm{hp}$ & 0.13 & 44 & $\mathrm{Fe}$ & GS & $\mathrm{RH}$ \\
\hline Rc & 7 & 1.33 & $\begin{array}{c}0.99- \\
1.79\end{array}$ & 0.06 & hp & 0.12 & 41 & $\mathrm{Fe}$ & $\begin{array}{l}-- \\
-\end{array}$ & --- & --- & --- & --- & --- & --- & --- & --- & --- \\
\hline Do & 7 & 1.24 & $\begin{array}{l}0.93- \\
1.65\end{array}$ & 0.14 & $\mathrm{hp}$ & 0.03 & 57 & $\mathrm{Re}$ & 6 & 1.39 & $\begin{array}{l}1.13- \\
1.70\end{array}$ & 0.002éû & $\mathrm{hp}$ & 0.23 & 28 & $\mathrm{Fe}$ & GS & $\mathrm{RH}$ \\
\hline Co & 7 & 1.17 & $\begin{array}{l}0.96- \\
1.44\end{array}$ & 0.12 & $\mathrm{hp}$ & 0.04 & 54 & $\mathrm{Re}$ & 5 & 1.34 & $\begin{array}{l}1.13- \\
1.58\end{array}$ & 0.0007éP & $\mathrm{hp}$ & 0.22 & 31 & $\mathrm{Fe}$ & GS & $\mathrm{RH}$ \\
\hline Allograft & & & & & Risk & & & & & & & & Risk & & & & & \\
\hline Ho & 7 & 0.75 & $\begin{array}{l}0.47- \\
1.19\end{array}$ & 0.22 & $\mathrm{de}$ & 0.27 & 20 & $\mathrm{Fe}$ & -- & --- & --- & --- & --- & --- & --- & --- & --- & --- \\
\hline Rc & 7 & 0.84 & $\begin{array}{c}0.55- \\
1.29\end{array}$ & 0.43 & de & 0.14 & 38 & $\mathrm{Fe}$ & -- & --- & --- & --- & --- & --- & --- & --- & --- & --- \\
\hline Do & 7 & 0.74 & $\begin{array}{l}0.55- \\
0.98\end{array}$ & $0.04 \hat{\mathrm{u}}$ & de & 0.46 & 0 & $\mathrm{Fe}$ & -- & --- & --- & --- & --- & --- & --- & --- & --- & --- \\
\hline Co & 7 & 0.89 & $\begin{array}{l}0.63- \\
1.25\end{array}$ & 0.48 & de & 0.02 & 60 & $\mathrm{Re}$ & 5 & 0.73 & $\begin{array}{c}0.56- \\
0.93\end{array}$ & $0.01 \hat{\mathrm{u}}$ & de & 0.16 & 39 & $\mathrm{Fe}$ & GS & $\mathrm{RH}$ \\
\hline
\end{tabular}

IL-18: interleukin-18 gene; GD: genotype distribution; Ho: homozygous; Rc: recessive; Do: dominant; Co:co dominant; $\mathrm{n}$ : number of studies; OR: odds ratio; CI: confidence interval; $\mathrm{P}^{\mathrm{a}}$ : P-value for association; in: increased risk; de: decreased risk; hp: higher in patients; $\mathrm{P}^{\mathrm{b}}$ : $\mathrm{P}$-value for heterogeneity; $\mathrm{I}^{2}$ : measure of variability; AM: analysis model; Re: random-effects; Fe: fixed-effects; PRO: pre-outlier; PSO: post-outlier; GS: gained significance; RH: reduced heterogeneity; values in bold indicate significant associations; é robust; all other significant outcomes were non-robust (Table 3); û significant outcomes that did not survive the Bonferroni correction; significant outcome that did $\mathrm{P}$

Table 3 Subgroup outcomes for $I L-18$ 


\begin{tabular}{cccc}
\hline $\begin{array}{c}\text { Test of } \\
\text { association }\end{array}$ & $\begin{array}{c}\text { Test of } \\
\text { heterogeneity }\end{array}$ & $\begin{array}{c}\text { Test of } \\
\text { association }\end{array}$ & $\begin{array}{c}\text { Test of } \\
\text { heterogeneity }\end{array}$
\end{tabular}

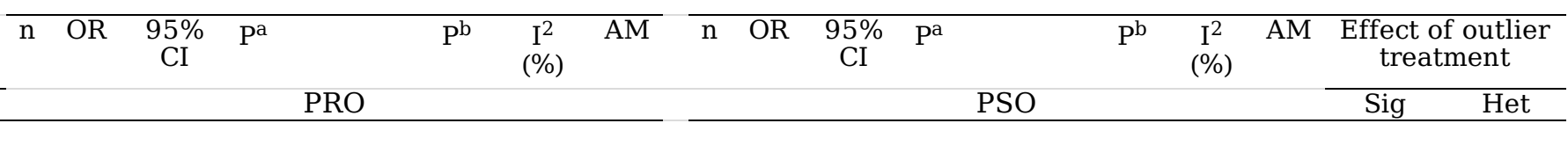

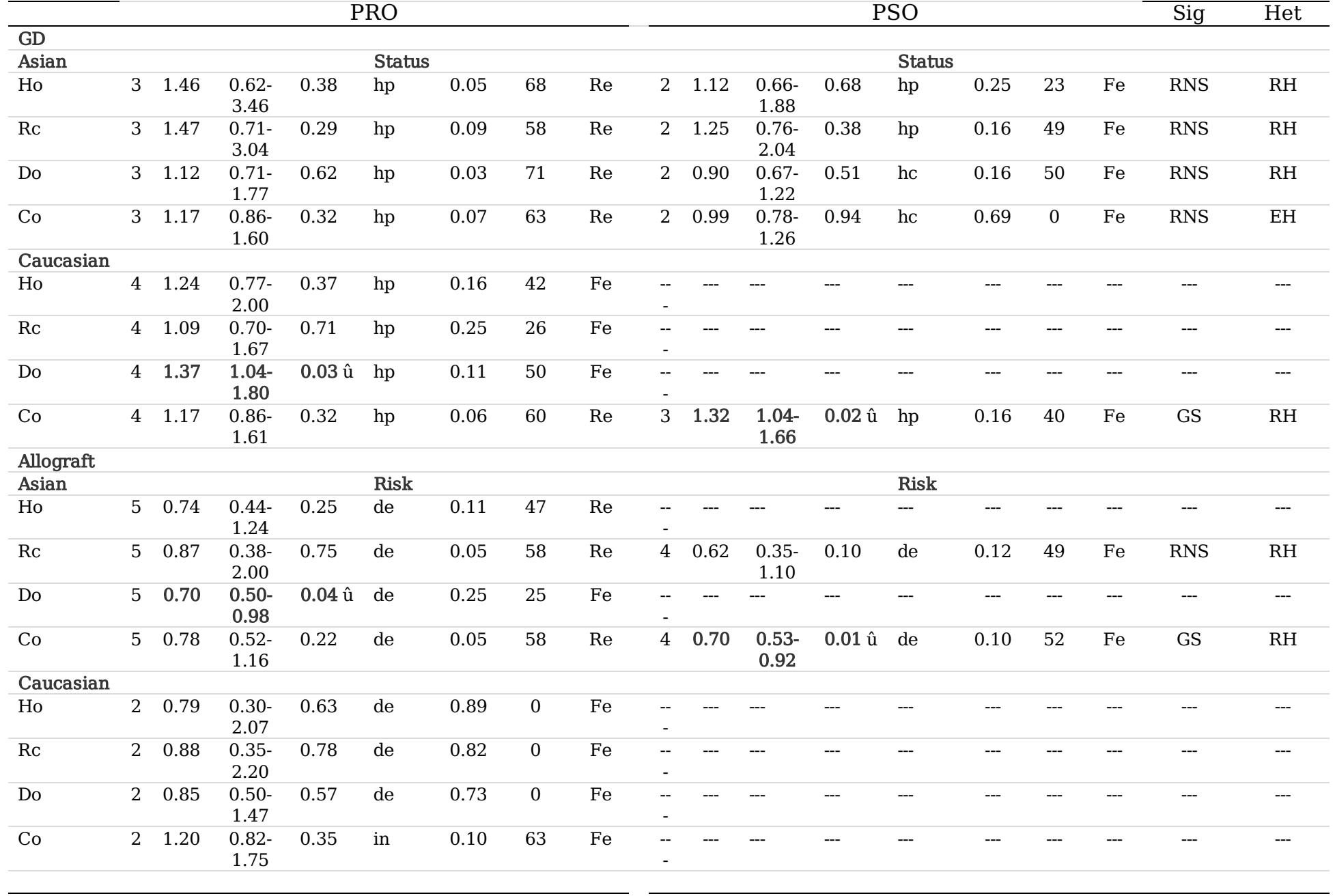

IL-18: interleukin-18 gene; GD: genotype distribution; Ho: homozygous; Rc: recessive; Do: dominant; Co:co dominant; n: number of studies; OR: odds ratio; CI: confidence interval; $\mathrm{P}^{\mathrm{a}}$ : P-value for association; in: increased risk; de: decreased risk; $\mathrm{P}^{\mathrm{b}}$ : $\mathrm{P}$-value for heterogeneity; $\mathrm{I}^{2}$ : measure of variability; AM: analysis model; Re: random-effects; Fe: fixed-effects; PRO: pre-outlier; PSO: post-outlier; GS: gained significance; RNS: retained nonsignificance; RH: reduced heterogeneity; EH: eliminated heterogeneity; values in bold indicate significant associations; hp: higher in patients; hc: higher in controls; all significant ORs were non-robust (Table 3); û significant outcomes that did not survive the Bonferroni correction

Table 4 Sensitivity analysis for $I L-18$ associations with KT outcomes 


\begin{tabular}{llllll}
\hline GD & Overall & PSO & Ho & 0.005 & {$[24]^{*}$} \\
\hline GD & Overall & PSO & Do & 0.002 & Robust \\
\hline GD & Overall & PSO & Co & 0.0007 & Robust \\
\hline Allograft & Overall & PRO & Do & 0.04 & {$[23,24]^{*}$} \\
Allograft & Overall & PSO & Co & 0.01 & {$[23,24]^{*}$} \\
GD & Caucasian & PRO & Do & 0.03 & {$[26]$} \\
\hline GD & Caucasian & PSO & Co & 0.02 & {$[26]$} \\
Allograft & Asian & PRO & Do & 0.04 & {$[23,24]^{*}$} \\
\hline Allograft & Asian & PSO & Co & 0.01 & {$[23,24]^{*}$} \\
\hline
\end{tabular}

IL-18: interleukin-18 gene; GD: genotype distribution; KT; kidney transplantation; PRO:

pre-outlier; PSO: post-outlier; Ho: homozygous; Do: dominant; Co: codominant; Pa: P-value

for association; Reference under sensitivity outcome indicates non-robustness; [24]* Mittal rs1946518; [23, 24]* Kim rs187238, Mittal rs187238; [26] do Nascimento rs187238 and rs1946518

\section{Figures}


September 24, 2019

"interleukin", "IL-18", "cytokine", "polymorphism", "allograft" and "kidney transplantation"

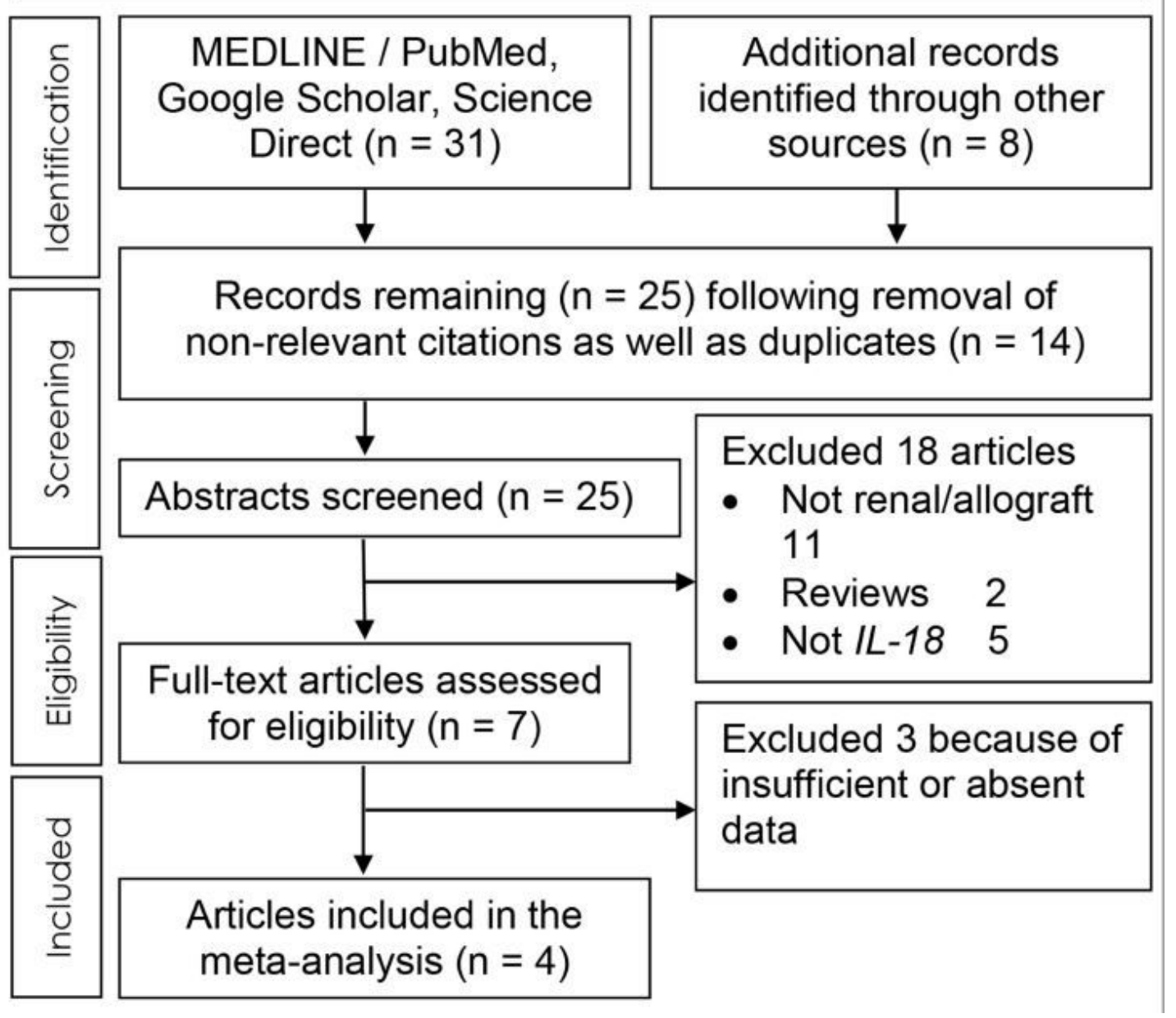

Figure 1

Summary flowchart of literature search

\begin{tabular}{|c|c|c|c|c|c|c|c|c|c|c|}
\hline \multirow[b]{2}{*}{ Study rs number } & \multicolumn{2}{|c|}{ Case } & \multicolumn{2}{|c|}{ Control } & \multirow{2}{*}{$\begin{array}{c}\text { Weight } \\
\%\end{array}$} & \multirow{2}{*}{$\begin{array}{r}\text { Odds Ratio } \\
\text { Random, } 95 \% \mathrm{Cl} \\
\end{array}$} & \multirow{2}{*}{\multicolumn{4}{|c|}{$\begin{array}{c}\text { Odds Ratio } \\
\text { Random, } 95 \% \mathrm{Cl}\end{array}$}} \\
\hline & Events & Total & Events & Total & & & & & & \\
\hline Kim rs187238 & 5 & 74 & 61 & 378 & 8.4 & $0.38[0.15,0.97]$ & & & & \\
\hline Kolesar rs187238 & 28 & 72 & 121 & 430 & 15.5 & $1.63[0.97,2.73]$ & & & & \\
\hline Kolesar rs1946518 & 21 & 60 & 166 & 430 & 14.5 & $0.86[0.49,1.51]$ & & & & \\
\hline Mittal rs187238 & 21 & 88 & 122 & 312 & 15.1 & $0.49[0.28,0.84]$ & & & & \\
\hline Mittal rs187238m & 34 & 72 & 105 & 230 & 15.3 & $1.07[0.63,1.81]$ & & & & \\
\hline Mittal rs1946518 & 30 & 88 & 119 & 312 & 16.0 & $0.84[0.51,1.38]$ & & & & \\
\hline Mittal rs1946518m & 33 & 72 & 92 & 228 & 15.2 & $1.25[0.73,2.13]$ & & & & \\
\hline Total $(95 \% \mathrm{CI})$ & & 526 & & 2320 & 100.0 & $0.89[0.63,1.25]$ & & & & \\
\hline Total events & 172 & & 786 & & & & & & & \\
\hline \multicolumn{7}{|c|}{$\begin{array}{l}\text { Heterogeneity: } \tau^{2}=0.13 ; \chi^{2}=15.16, d f=6\left(P^{\mathrm{v}}=0.02\right) ; I^{2}=60 \% \\
\text { Test for overall effect: } Z=0.70\left(P^{\mathrm{a}}=0.48\right)\end{array}$} & 0.2 & $\begin{array}{l}0.5 \\
\text { reduced risk }\end{array}$ & $\begin{array}{cc}1 & 2 \\
& 2 \\
\text { increased risk }\end{array}$ & 5 \\
\hline
\end{tabular}

Figure 2

Forest plot outcome in the allograft analysis of the Co model. Diamond denotes the pooled odds ratio (OR) indicating reduced risk (0.89). Squares indicate the OR in each study. Horizontal lines on either side of each square represent the $95 \%$ confidence intervals (CI). The Z test for overall effect was non-significant $(\mathrm{Pa}=0.48)$. The $\chi 2$-test shows the presence of heterogeneity $(\mathrm{Pb}=0.02, \mathrm{I} 2=60 \%) ; \mathrm{I}$ : a measure of variability expressed in \%; m: controls matched with cases 


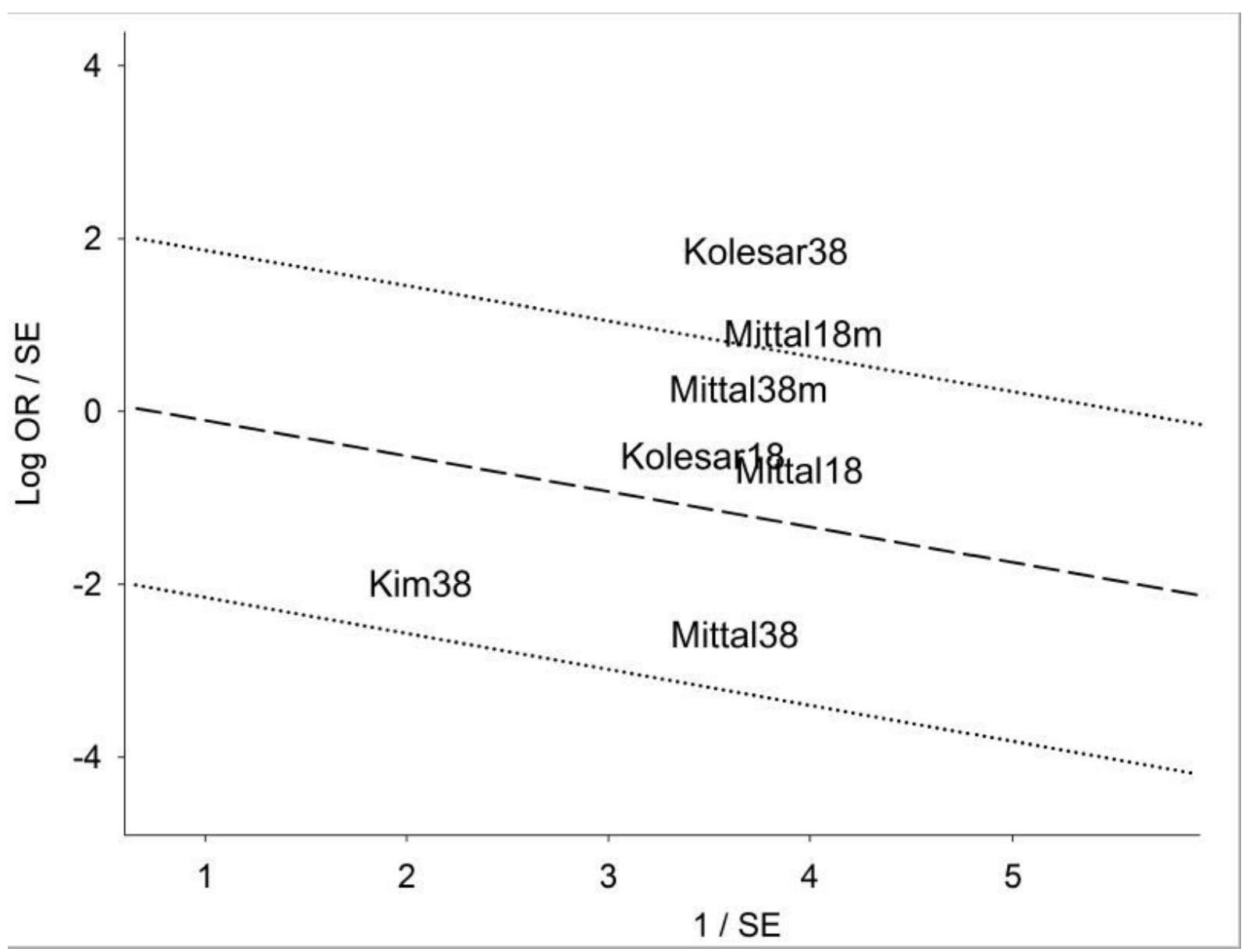

\section{Figure 3}

Galbraith plot of the allograft analysis in the Co model. Log OR: logarithm of standardized odds ratio; SE: standard error; The two studies above the +2 confidence limit are the outliers; $m$ : controls matched with cases

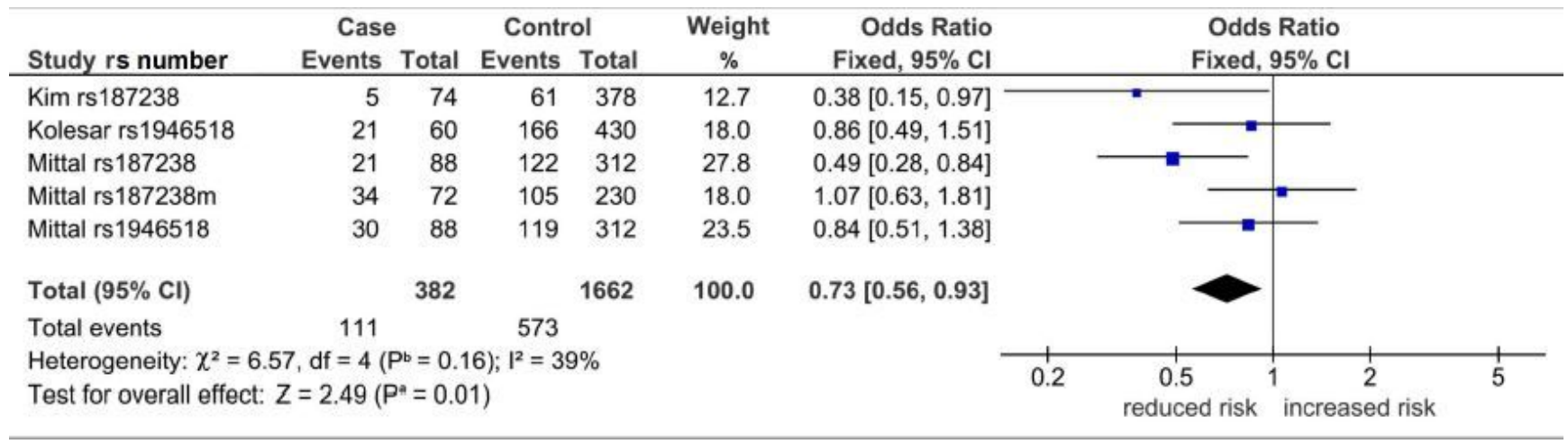

\section{Figure 4}

Forest plot outcome of outlier treatment in the allograft analysis of the Co model. Diamond denotes the pooled odds ratio (OR) reduced risk (0.73). Squares indicate the OR in each study. Horizontal lines on either side of each square represent the $95 \%$ confidence intervals (CI). The $Z$ test for overall effect shows significance $(\mathrm{Pa}=0.01)$. The $\chi 2$-test indicates reduced heterogeneity $(\mathrm{Pb}=0.16, \mathrm{I} 2=39 \%) ; \mathrm{I}$ : a measure of variability expressed in \%; $\mathrm{m}$ : controls matched with cases 